\title{
Characteristics of Ti6Al4V Powders Recycled from Turnings via the HDH Technique
}

\author{
Mertol Gökelma ${ }^{1, *}$, Dilara Celik ${ }^{2}$, Onur Tazegul ${ }^{2}$, Huseyin Cimenoglu ${ }^{2}$ \\ and Bernd Friedrich 3 (iD \\ 1 Department of Materials Science and Engineering, Norwegian University of Science and Technology, \\ Trondheim 7491, Norway \\ 2 Department of Metallurgical and Materials Engineering, Istanbul Technical University, Sariyer, \\ Istanbul 34469, Turkey; dilaracelik01@gmail.com (D.C.); tazegul@itu.edu.tr (O.T.); \\ cimenogluh@itu.edu.tr (H.C.) \\ 3 IME Process Metallurgy and Metal Recycling, RWTH Aachen University, Intzestraße 3, \\ Aachen 52056, Germany; bfriedrich@ime-aachen.de \\ * Correspondence: mertol.gokelma@ntnu.no; Tel.: +47-73-412-926
}

Received: 28 March 2018; Accepted: 7 May 2018; Published: 9 May 2018

\begin{abstract}
The objective of this research is for Ti6Al4V alloy turnings, generated during the machining of implants, to produce powders for the fabrication of Ti base coating via the cold spray method. In order to decrease the cost of powder production and increase the recycling rate of the turnings, the hydrogenation-dehydrogenation $(\mathrm{HDH})$ process has been utilised. The HDH process consists of the following sequence: surface conditioning of the turnings, hydrogenation, ball milling (for powder production), and dehydrogenation. Afterwards, the properties of the recycled powder were analysed via phase, chemical, and morphological examinations, and size and flowability measurements. Usability of the powder in additive manufacturing applications has been evaluated via examining the characteristics of the deposit produced from this powder by the cold spray method. In short, promising results were obtained regarding the potential of the recycled powders in additive manufacturing after making minor adjustments in the $\mathrm{HDH}$ process.
\end{abstract}

Keywords: Ti6Al4V; HDH; powder metallurgy; powder synthesis

\section{Introduction}

Ti6Al4V alloy (Ti, 6 wt. \% Al, 4 wt. \% V) is $\alpha+\beta$ phase titanium alloy, which occupies about $50 \%$ of the total titanium market [1,2]. It is very commonly used in aerospace, automotive, and medical industries, due to its high strength/weight ratio, corrosion resistance, biocompatibility, and low thermal expansion characteristics. Although Ti6Al4V alloy is a high-cost material it has a loss of about $70-80 \%$ as scrap while manufacturing of engineering components [3]. Owing to the high oxygen affinity, recovery of titanium-based scraps by re-melting is a difficult and costly process. Furthermore, re-melting may cause an imbalance in alloy composition. From this point of view recovery of titanium scraps in the form of powder by following the powder metallurgy route can be attractive especially for the recently-growing additive manufacturing market (such as 3D printing and cold-spray applications, etc.). Thus, powder metallurgy of Ti6Al4V alloy can be an alternative method either to use powder as the starting material or to recycle the new scrap which comes from semi-fabrication and manufacturing operations as the powder with improved purity [4,5].

The additive manufacturing industry has been growing very quickly in recent years and reached US\$5.1 billion in 2015 [6]. This increasing trend requires more input material and new production methods fulfil the requirements for Ti6Al4V powders. There are many additive manufacturing 
technologies in the market and the main methods are stereolithography, selective laser sintering, direct metal laser sintering, fused deposition modelling, and 3D printing [7]. 3D printing has been improved with many ongoing studies and it is expected to be used more commonly in the future [8].

It has been documented that, owing to the high oxidation tendency of atomization, a titanium melt can be made under vacuum or inert gas atmosphere at high production costs by utilising special technologies, such as electrode induction melting gas atomization, vacuum arc melting and cold hearth melting, etc. [9]. As an alternative method hydrogenation/dehydrogenation (HDH) can be an economical option for the recycling of titanium based scraps [10]. The HDH method benefits from room temperature embrittlement of the hydrate and produces powder-sized hydrate which must be dehydrated to produce the final powder product. The balance pressure and the temperature of the system are the main parameters for hydride transformation. The typical reaction can be written as $M+H_{2} \leftrightarrow M_{2}$ and can be reversed by the balance pressure of hydrogen gas. If the pressure is above the equilibrium pressure, hydrogen atoms enter the lattice to form metal hydrate; if it is below that level, hydrogen atoms diffuse out from the metal to from hydrogen gas [8,9]. During the hydration, some hydrogen atoms $(\mathrm{H})$ enter the crystal lattice under the critical temperature and pressure. Then, while cooling under room temperature, hydrogen atoms are diffused into the crystal lattice and occupy the tetrahedral sites [11]. When titanium-based scraps are of concern, this mostly occurs in the $\beta$-Ti phase, which has more hydrogen solubility than the $\alpha$-Ti phase [10-13]. Enrichment of the material by hydrogen (hydrogenation) imposes embrittlement leading to fracturing under mechanical loads (i.e., during ball milling), subsequent dehydrogenation provides some ductility as the result of outward diffusion of hydrogen. After dehydrogenation, powders must be kept under the protective atmosphere because of the oxidation affinity of the titanium. There are many studies that sintered the hydrogenated powder and performed the dehydrogenation step after the final shape was given by sintering [2,14-17].

The current work aims to present the preliminary results of Ti6Al4V powder production via the $\mathrm{HDH}$ method. Powder characteristics are analysed and its performance as a coating material has been evaluated. This study presents an innovation beyond the state of the art which is based on the usage of recycled Ti6Al4V scrap as a material for coating and/or additive manufacturing.

\section{Experimental Methodology}

In this study turnings produced during manufacturing of Ti6Al4V-ELI ( $0.20 \mathrm{wt}$. \% of oxygen) implants were used as the scrap. Figure 1 presents flow chart for production of Ti6Al4V powder, which starts with an etching process to clean and activate the surface of the turnings. The turnings were then hydrogenated to form a brittle titanium hydrate for easy milling down to a size of less than $100 \mu \mathrm{m}$. Then powders of Ti6Al4V were dehydrogenated as a final step. The produced powder is characterized at the end to evaluate the usability of the product for different targets. Additionally, deposition performance of the recycled powder was analysed by low-pressure cold spray equipment.

Acid cleaning of the turning was made in $\mathrm{H}_{2} \mathrm{SO}_{4}: \mathrm{H}_{2} \mathrm{O}$ solution (having a ratio of 1:6) to activate their surfaces by removing any organic or inorganic impurities. After washing with deionised water and drying at $60{ }^{\circ} \mathrm{C}$ for about $45 \mathrm{~min}$ turnings were placed into the chamber of the reactor for hydrogenation. Hydrogenation was performed under 2.5 bar hydrogen atmosphere and the turnings were heated at a rate of $400{ }^{\circ} \mathrm{C} / \mathrm{h}$ up to about $700{ }^{\circ} \mathrm{C}$. After reaching a peak temperature of $700{ }^{\circ} \mathrm{C}$ the reactor was switched off and the turnings were allowed to cool to room temperature in the reactor. Diffusion of hydrogen into the turnings (activation) started around $470{ }^{\circ} \mathrm{C}$ according to Figure 2, representing the applied hydrogenation process as a "temperature vs. time" plot. The activation can be observed by the increasing temperature with a higher rate. After switching off the reactor temperature remained at about $600{ }^{\circ} \mathrm{C}$ for a certain interval as a result of the exothermic reaction imposed by the diffusion of hydrogen atoms. Then hydrated turnings were milled at room temperature in the steel ball milling equipment (MM 301, Retsch GmbH, Haan, Germany) with the frequency of $20 \mathrm{~s}^{-1}$ for up to four minutes and sieved under $100 \mu \mathrm{m}$. 


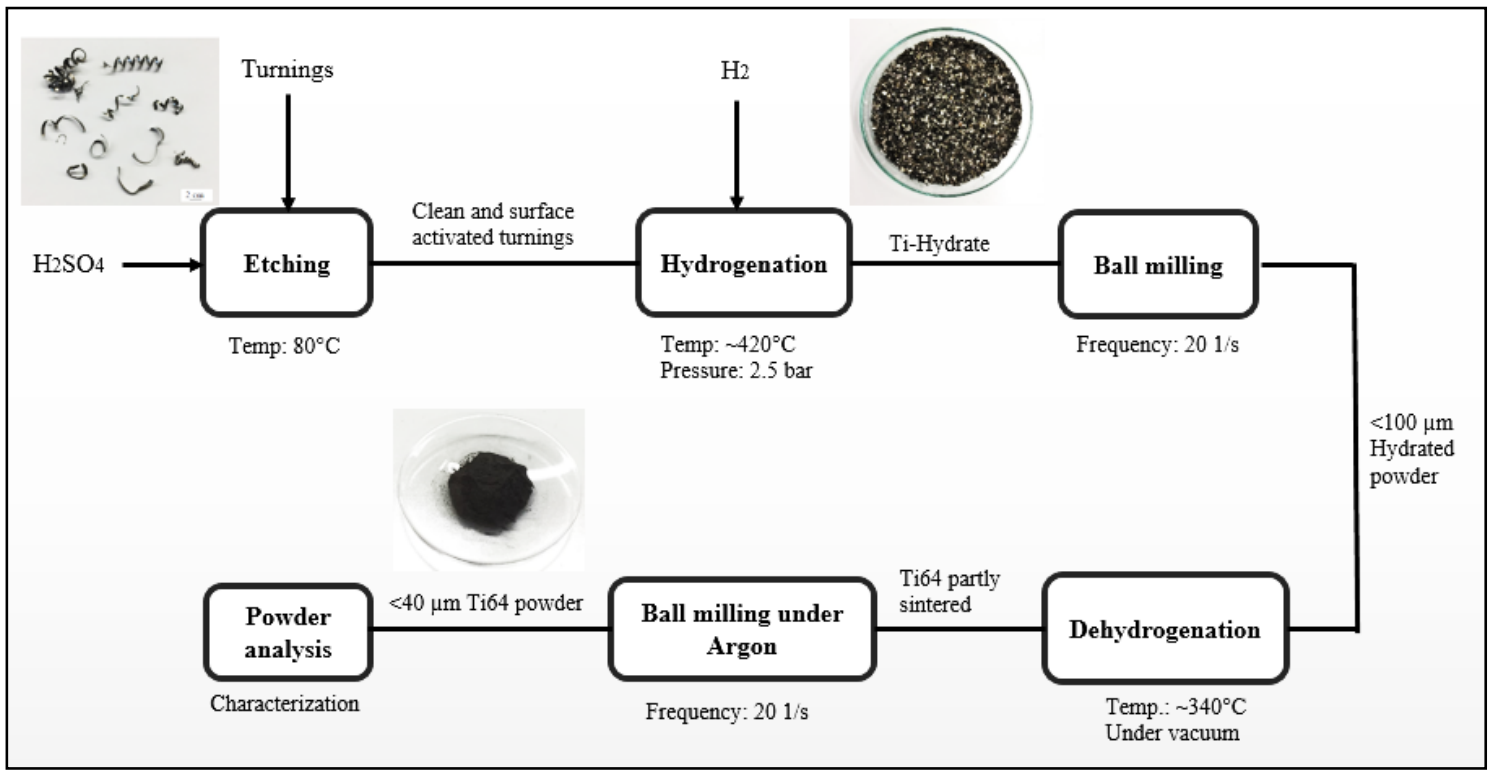

Figure 1. Experimental procedure of powder production via the $\mathrm{HDH}$ process.

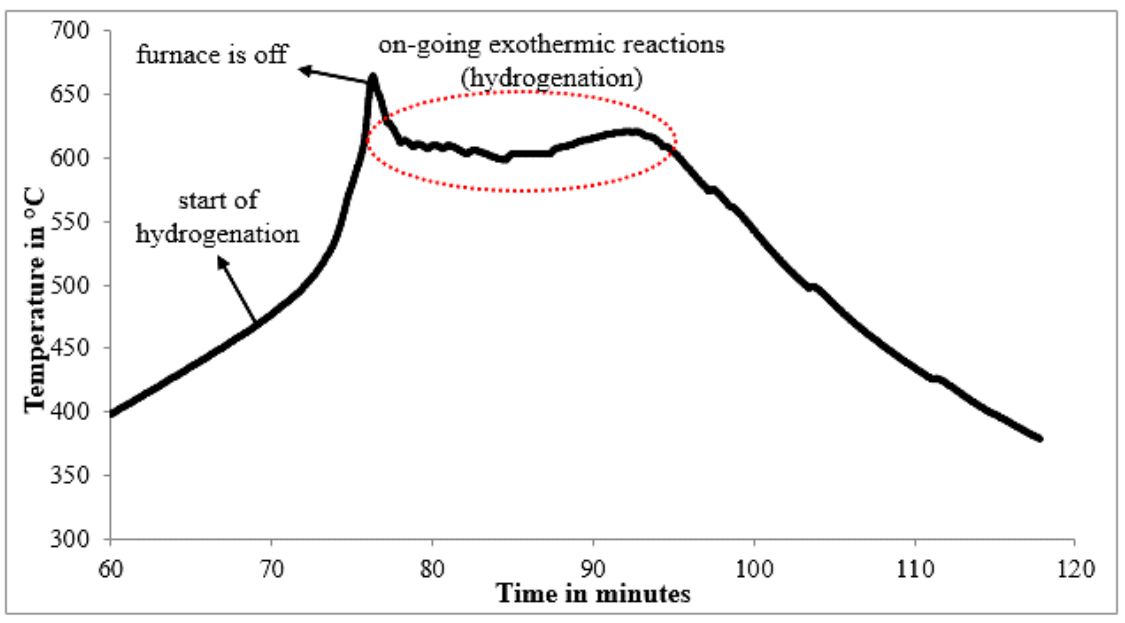

Figure 2. Temperature measurement time during hydrogenation of the Ti6Al4V turnings.

The sieved powder was placed again in the same reactor for dehydrogenation under continuous vacuum. By the time, the system was cooled down under vacuum (1 mbar) to room temperature. Figure 3 presents the variation of temperature and pressure with respect to dehydrogenation duration. While the heating rate was gradually increasing to the peak temperature of about $700{ }^{\circ} \mathrm{C}$ pressure increased after $95 \mathrm{~min}$ as the result of the start of dehydrogenation. Pressure gradually increased for a duration of about $110 \mathrm{~min}$, above which it sharply increased to over-pressure (1000 mbar is the detection limit of the unit) due to the high amount of hydrogen release. After switching off the reactor pressure sharply reduced while temperature gradually decreased. The dehydrogenised powder was taken out from the reactor in a glovebox with the oxygen concentration of $<30 \mathrm{ppm}$. It was noticed that the powder was loosely sintered during the dehydrogenation process. Therefore, the dehydrated powder was milled once again in the steel-ball milling unit under an argon atmosphere. After a final sieving, the powder under $45 \mu \mathrm{m}$ is sent for characterization. 


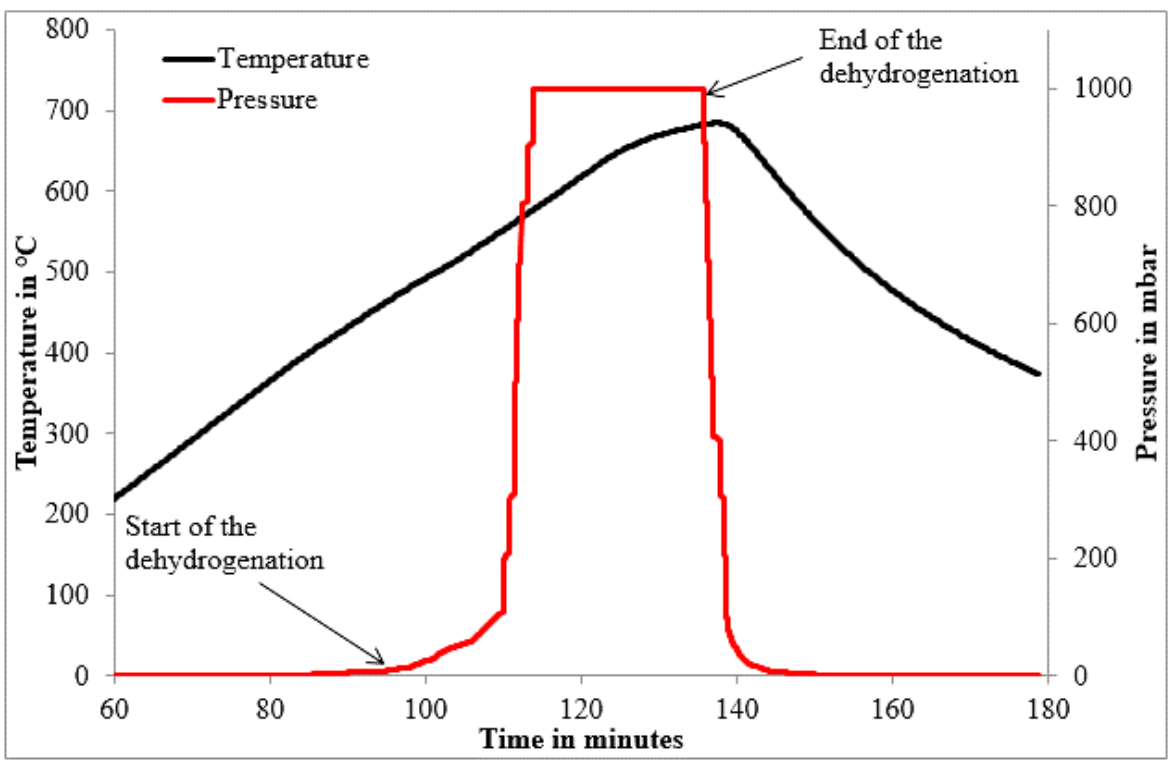

Figure 3. Temperature measurement time during dehydrogenation of the hydrate powders.

The recycled powder was characterized by the following methods: elemental analysis by atomic absorption (for $\mathrm{Al}, \mathrm{V}, \mathrm{Fe}$ ) solid state infrared absorption (for oxygen) and thermal conductivity (for hydrogen), phase analysis by XRD (X-ray Diffraction, Bruker ${ }^{\mathrm{TM}} \mathrm{D} 8$ Advance Series $35 \mathrm{kV}$ $40 \mathrm{~mA}$, Billerica, MA, USA), flowability measurement by AOR (angle of repose), morphology by SEM (scanning electron microscope, JEOL ${ }^{\mathrm{TM}}$ JCM-6000Plus NeoScope, Peabody, MA, USA) and particle size distribution by laser diffraction (Mastersizer 2000, Malvern Panalytical, Worcestershire, UK). Additionally, deposition efficiency of the powder on commercial purity titanium substrates by low pressure (600 kPa) cold gas dynamic spray equipment (Rusonic Model K201, Rus Sonic Technology, Arcadia, CA, USA) having a converging-diverging tubular nozzle was evaluated. Characteristics of the deposits were determined by SEM examinations and XRD analysis.

\section{Results}

Figures 4 and 5 present the size distribution and morphology of the powder recycled from Ti6Al4V-ELI turnings, respectively. Fifty percent of the powder is under $13 \mu \mathrm{m}$ and $90 \%$ is under $37 \mu \mathrm{m}$. The morphology of the particles is irregular, as expected, with the circularity of $0.72 \pm 0.04$ and the form factor of $1.42 \pm 0.15$ (max-axis/min-axis) [18]. The flowability of the powder was measured as $38.93 \pm 1.55$, which is accepted as "fair-aid not needed" or "some cohesiveness" [19].

The elemental composition of the powder is given in Table 1 along with the standard composition of Grade 5 and Grade 23 Ti6Al4V alloys. In general, the concentrations of the alloying elements are in an acceptable range according to the standards of ASTM B988-13 Grade 5, except the hydrogen content. Additionally, the average oxygen content of the dehydrogenated powder is slightly higher than that prescribed by ASTM B988-13 Grade 5. Moreover, oxygen and hydrogen contents of dehydrogenated powder are not in the range of Grade 23, which is called extra low interstitial (ELI). 


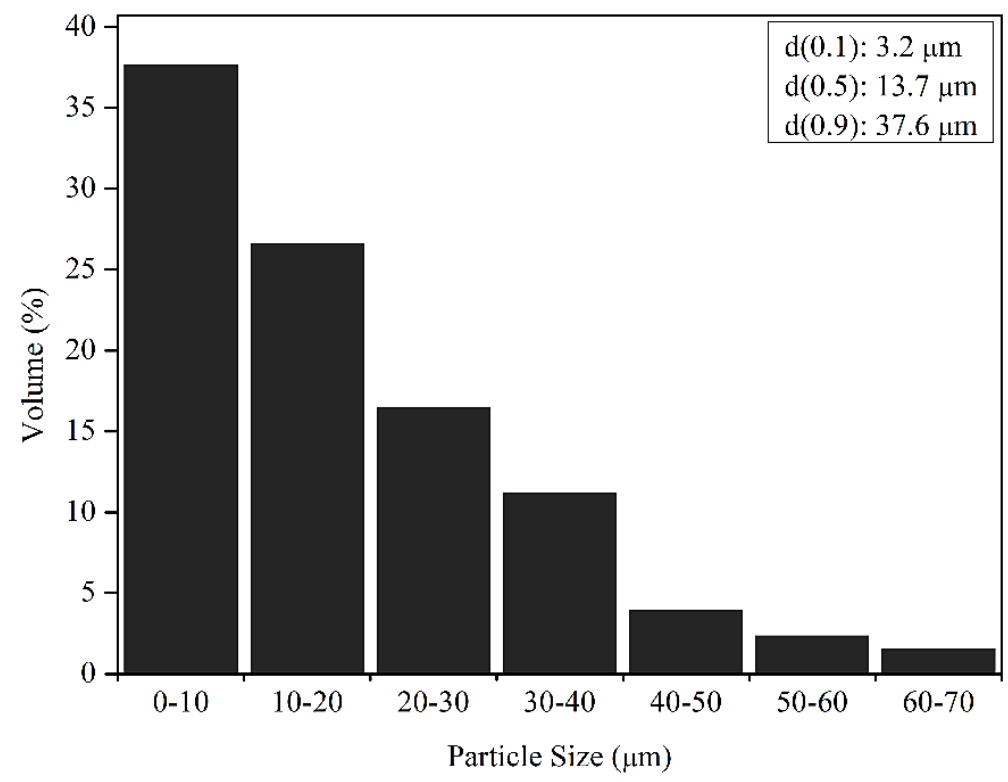

Figure 4. Size distribution of Ti6Al4V particles synthesized by the HDH method.

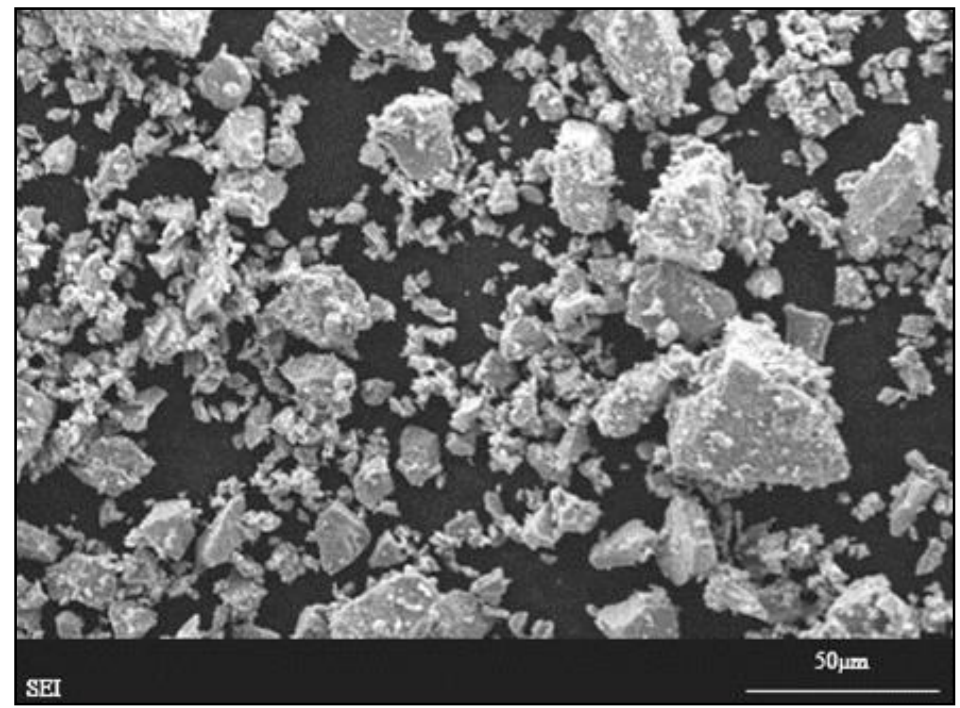

Figure 5. Electron microscopy picture of powder synthesized by the HDH method.

Table 1. Elemental analysis of dehydrogenated powder and relevant standards.

\begin{tabular}{ccccccc}
\hline Sample & $\begin{array}{c}\text { Al } \\
\text { wt. } \%\end{array}$ & $\begin{array}{c}\text { V } \\
\text { wt. } \%\end{array}$ & $\begin{array}{c}\text { Fe } \\
\text { wt. } \%\end{array}$ & $\begin{array}{c}\text { O } \\
\text { wt. } \%\end{array}$ & $\begin{array}{c}\text { H } \\
\text { wt. \% }\end{array}$ & $\begin{array}{c}\text { Ti } \\
\text { wt. } \%\end{array}$ \\
\hline Dehydrogenated powder & $5.57 \pm 0.6$ & $3.97 \pm 0.5$ & $0.2 \pm 0.09$ & $0.32 \pm 0.15$ & $0.06 \pm 0.03$ & balance \\
ASTM B265-15/B348-13/B381-13 & $5.5-6.5$ & $3.5-4.5$ & $0.25 \mathrm{max}$ & $0.13 \mathrm{max}$ & $0.0125 \mathrm{max}$ & balance \\
$\begin{array}{c}\text { Grade 23 [20-22] } \\
\text { ASTM B988-13 Grade 5 [23] }\end{array}$ & $5.5-6.75$ & $3.5-4.5$ & $0.4 \mathrm{max}$ & $0.3 \mathrm{max}$ & $0.015 \mathrm{max}$ & balance \\
\hline
\end{tabular}

XRD patterns of the as-received turnings, and powders (in hydrogenised and dehydrogenised states) are shown in Figure 6. The turnings consisted of $\alpha$ and $\beta$-Ti phases as expected. On the XRD patterns of the powders peaks of titanium hydrides (in the form of $\mathrm{TiH}_{2}$ and $\mathrm{TiH}_{1.5}$ ) appeared. As compared to the hydrogenised state, dehydrogenation caused domination of $\alpha$ and $\beta$-Ti phase peaks along with peaks of titanium hydrides by considering the intensity ratios of the Ti peaks with 
those of $\mathrm{TiH}_{1.5}$ and $\mathrm{TiH}_{2}$. However, the applied dehydrogenation process did not completely remove titanium hydrides from the powders.

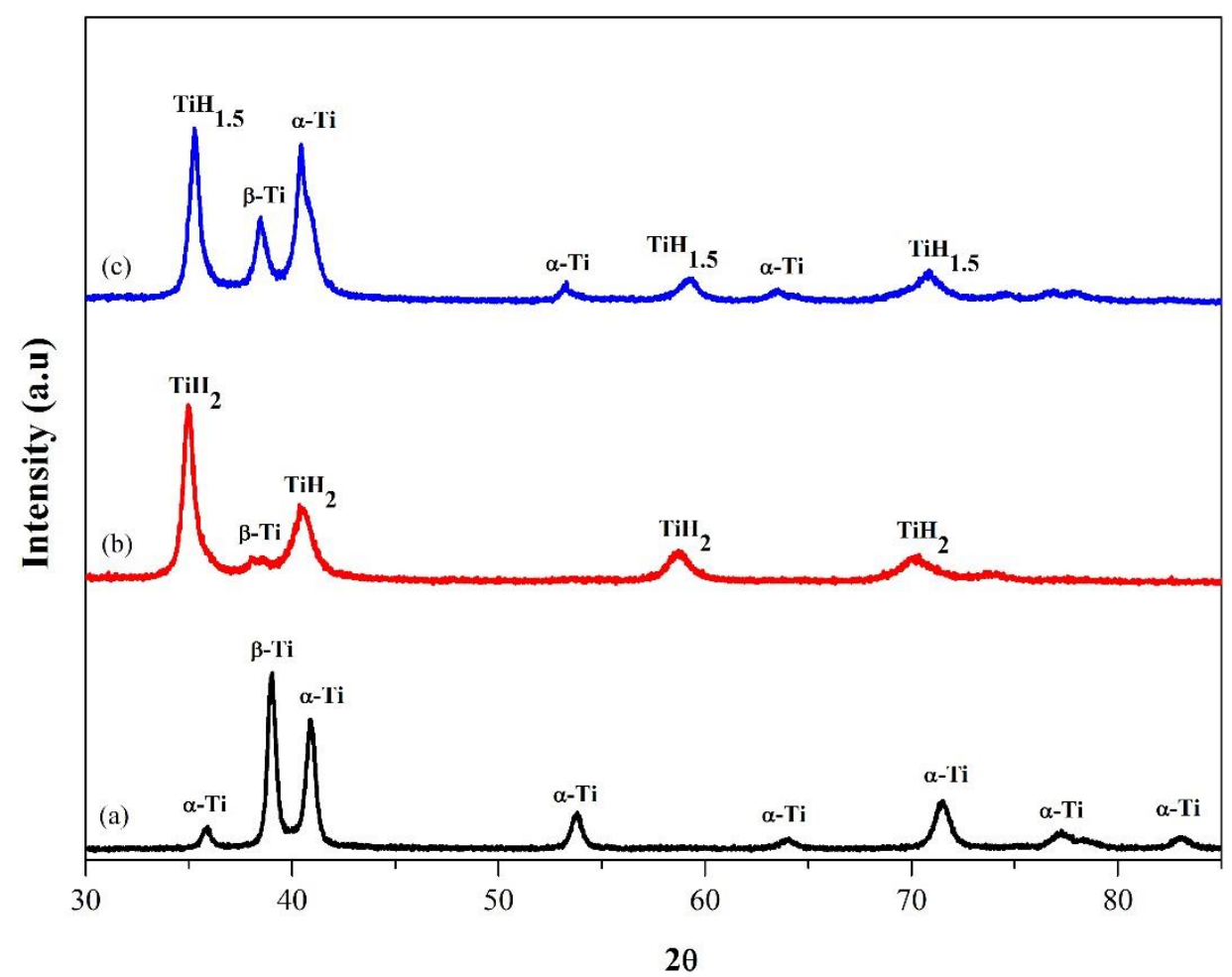

Figure 6. X-ray diffraction analysis of the raw material (a), after hydrogenation (b), and after dehydrogenation (c).

In order to evaluate the deposition characteristics of the recycled powder, some attempts have been made by the cold spray method which is based on the acceleration of particles in a process gas over the supersonic velocity through the convergent-divergent type nozzle [24,25]. In this system, particles of the feedstock powder are deposited as they impact on the surface of the substrate [24]. The bonding of the cold sprayed powder is a result of the mechanical interlocking between cold sprayed particles and the substrate. Increasing of the coating thickness is provided by the deposition of the following particle on the previous ones. In this process air, argon, helium, or nitrogen can be used as the process gas. In terms of acceleration capability and applicability, helium is the most favourable for high deposition efficiency. On the other hand, air appears as the best option when the cost of the coating is of concern. For those reasons, helium and air have been chosen as the process gases in this study to evaluate the deposition characteristics of the recycled powder with the parameters listed in Table 2. It should be emphasized that recycled powder was not successfully deposited with the utilized low pressure cold spray equipment over commercial purity titanium (Cp-Ti) with air as the process gas, unlike He. This observation can be associated with approximately three times higher acceleration capability of helium as compared to that of air due to its low molecular weight [24]. In order to overcome this problem $3 \mathrm{wt}$. \% $\mathrm{Al}$ has been added into the feedstock as a binder according to our experience when using air as the process gas [26]. Additionally, the traverse speed has been reduced five times to further assist the binding of the feedstock in air. 
Table 2. Low-pressure coating parameters of cold spray process.

\begin{tabular}{ccc}
\hline Carrier Gas & He & Air \\
\hline Feedstock & Recycled powder & 97 wt. \% Recycled powder + 3 wt. \% Al \\
Gas pressures (bar) & 6 & 6 \\
Traverse speed (mm/s) & 5 & 1 \\
Number of pass & 3 & 2 \\
Beam distance $(\mathrm{mm})$ & 2 & 2 \\
Standoff distance $(\mathrm{cm})$ & 1 & 1 \\
\hline
\end{tabular}

A cross-section of the coatings deposited on the Cp-Ti substrate by cold spraying of the powder produced is shown in Figure 7. When He was used as the process gas powders were deposited on the substrate without remarkable discontinuities at the coating/substrate interface. However, a high amount of porosity was detected within the coating showing lower integration among powder particles. When air was used as the process gas successful deposition was not obtained unless addition of aluminium powder (at concentration of $3 \mathrm{wt}$. \%) into the feedstock was done. Thus, $\mathrm{Al}$ acted as a binder for successful deposition of the powder on $\mathrm{Cp}$-Ti (without noticeable porosities in the coating and discontinuities at the coating/substrate interface) when air was used as the process gas. In this respect, the dark coloured regions in the coating shown in Figure $7 \mathrm{~b}$ were identified as Al particles by EDX (Energy-dispersive X-ray spectroscopy) analysis conducted during SEM surveys.
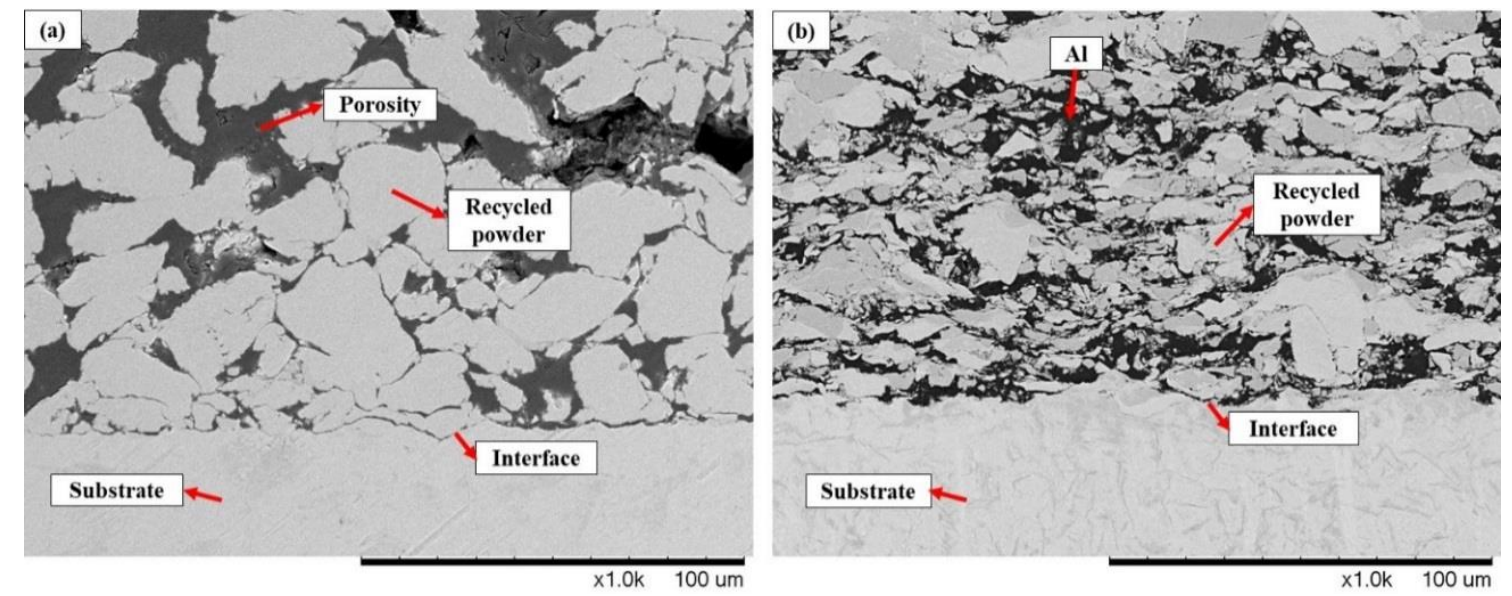

Figure 7. SEM micrographs of cold spray deposits produced by utilization of (a) He and (b) air as process gases (deposition parameters are listed in Table 3).

XRD patterns of the deposits shown in Figure 7 are depicted in Figure 8. Peaks of $\mathrm{TiH}_{1.5}$ and $\mathrm{Ti}$ were detected on the XRD pattern of the deposit formed by using He as the process gas (Figure 8a). Since $\mathrm{Al}$ powder has been added into the feedstock, additional Al peaks appeared on the XRD pattern of the deposit produced by utilization of air as the process gas (Figure $8 \mathrm{~b}$ ). It should be noted that the peaks of $\mathrm{TiH}_{1.5}$ which were detected in the XRD pattern of the recycled powder (Figure $6 \mathrm{c}$ ) also remained after the cold spray process. 


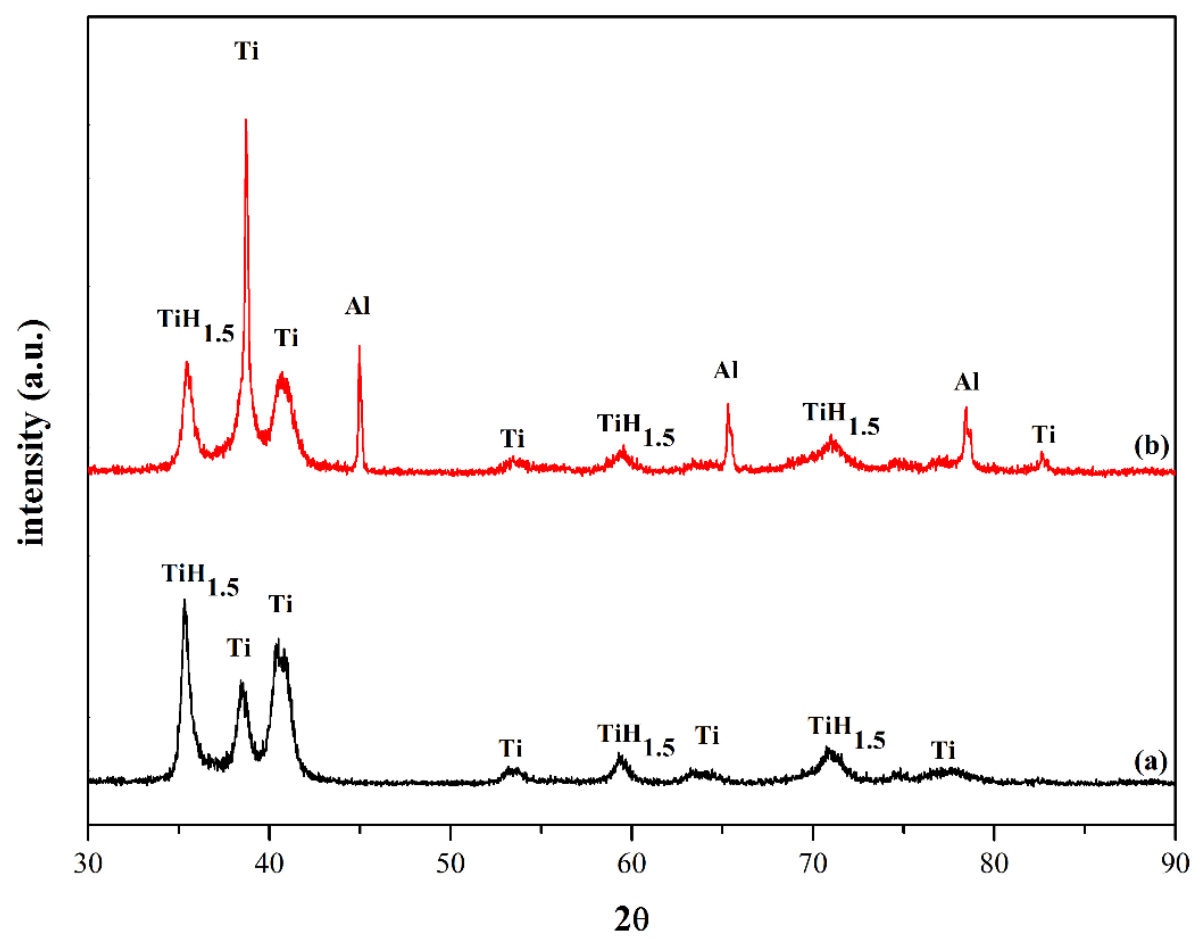

Figure 8. X-ray diffraction patterns of the coatings deposited by using (a) He and (b) air as the process gas.

\section{Discussion}

Ti6Al4V powder recycled from turnings via the $\mathrm{HDH}$ method have a mostly irregular morphology, which is also shown in this study. In spray-based deposition processes, like the cold spray method, irregular powders favour higher particle velocities than spherical ones because of their higher drag force [27-30]. In this respect, irregular powder particle morphology has some advantage on the final product of the cold-spray method [31]. In contrast, spherical particle morphology is more desirable than irregular ones for 3D printing, in terms of flowability requirements of the process [32-34]. Flowability is mostly related to the particle shape of the powder. Irregular shapes generally have lower flowability as compared to spherical ones. Although, the smaller-sized particles would have an acceptable flowability range, decreasing the particle size under the critical level could affect the productivity of the dehydrogenation process [34]. Apart from there being no special requirement of flowability for the cold spray process, the mean particle size, and the oxygen and nitrogen contents of the powder are more important factors for good coating properties and deposition efficiency [27]. When the average particle size is of concern, the HDH method provided an average particle size $\left(\mathrm{d}_{0.5}\right)$ of $13.7 \mu \mathrm{m}$, which is within the acceptable range for almost every coating method and additive manufacturing processes [18]. The interstitials, such as oxygen and nitrogen in the powder, deteriorate the deposition efficiency by reducing the plastic deformation capacity of the Ti powders [35].

Even after dehydrogenation $\mathrm{TiH}_{1.5}$ still remains in the Ti6Al4V powder. This result matches with the research of Bhosle et al. [34], where they reported that the dehydrogenation occurs in a two-step process: $\mathrm{TiH}_{2} \rightarrow \mathrm{TiH}_{\mathrm{x}} \rightarrow \alpha-\mathrm{Ti}$. The finer hydride particles contain lower hydrogen in the second hydride phase $\left(\mathrm{TiH}_{\mathrm{x}}\right)$ and they are thermally more stable at higher temperatures than the $\mathrm{TiH}_{2}$ phase, which may result in the remaining hydrates even after the dehydrogenation process. This is also caused by a poor vacuum setup. In Table 3 the parameters of vacuum, temperature, and duration are listed for successful dehydrogenation of titanium powder from previous study, suggesting that higher vacuum or longer duration would provide complete dehydrogenation of the powder obtained by recycling. Moreover, it should be noted that the XRD peaks shifted to lower angles as compared to 
that of the turnings due to the heavy deformation imposed during the ball milling process applied after hydrogenation. Additionally, the oxygen content of the recycled powder should be minimized according to the relevant standards [20-23]. The oxygen content is slightly higher than the desired range for the standard B265-15/B348-13/B381-13, but it is an acceptable range for the standard B988-13. After the HDH process, Ti6Al4V alloy powder should be within the chemistry limits of international standards and correspond to the industrial specification, which include medical, aerospace, and defence applications [12]. One of the important parameters to be considered to reduce the oxygen content is the vacuum level applied during the hydrogenation stage. Oxidation of very fine hydrate particles during milling can also be a source of oxygen due to very high surface area [36]. Therefore, it is suggested that adjusting the vacuum level and processing time of the dehydrogenation stage could also provide a solution for reducing the oxygen level of the recycled powder, which the process needs during dehydrogenation.

Table 3. Important dehydration parameters used in different researches.

\begin{tabular}{cccc}
\hline Sample & Vacuum $(\mathbf{P a})$ & Temperature $\left({ }^{\circ} \mathbf{C}\right)$ & Duration (Hour) \\
\hline Titanium rod [10] & $6.7 \times 10^{-3}$ & 700 & 2 \\
Titanium sponge [36] & $10^{-2}$ & 625 & 3 \\
Titanium sponge [37] & $8 \times 10^{2}$ & 700 & 36 \\
\hline
\end{tabular}

Deposition characteristic of the recycled powder have been analysed by using the low-pressure cold spray method. Usage of helium as a process gas generated a deposit with relatively high porosity content. It is possible to improve the quality by using high-pressure cold spray systems generating higher velocities as compared to low-pressure cold spray systems. Moreover, reducing the hydrogen and oxygen content of the recycled powder, which imposes brittleness, would lead to the generation of denser deposits even by utilizing air as the process gas (without the addition of Al powder). Irregular morphology of the recycled powder also affected the deposition capacity. Although these powders can reach higher velocity than spherical ones $[29,31]$, it is not possible to have a dense coating because of the irregularity. In summary, the coating trials gave promising results about the usability of the Ti6Al4V powder recycled from scrap via the HDH process. However, some adjustments are necessary to increase the success of this powder in additive manufacturing processes.

\section{Conclusions}

The results of the current work can be summed up in the following points:

- Morphology of the powders synthesized by the HDH method is irregular and perfect spherical shapes cannot be achieved. However, in the future the morphology of the powder can be changed by using an extra spheroidization process at the end.

- The particle size of the recycled powder product is under $45 \mu \mathrm{m}$. The size distribution is suitable to use in both additive manufacturing and coating methods. The average particle size and range of powder could be changed by using different milling conditions according to the further process where the powder will be used.

- The concentration of alloying elements, such as $\mathrm{Al}, \mathrm{V}$, and $\mathrm{Fe}$, is in an acceptable range in terms of standards. However, the oxygen content of the final powder is near the acceptable limit of the Grade 5 standard, but this content could be reduced by using better vacuum conditions to reduce the air concentration in the reactor. Optimizing the particle size distribution and more effective dehydrogenation parameters could reduce the oxygen content. Furthermore, the hydrogen level is higher than the specified range $(0.06 \pm 0.03 \mathrm{wt}$. \%) of the relevant standards due to the remaining hydrate phases in the powder. Therefore, the dehydrogenation procedure applied in this study must be improved (better vacuum, longer dehydrogenation time, optimized particle size range) to remove all hydrate phases. 
- Low pressure cold spray deposition studies revealed the potential of the powders obtained by the HDH process for coating. In order to evaluate the usability of this powder produced from turnings scrap, the characteristics of the deposits from this powder are being investigated and the results will be presented in a follow-up publication.

Author Contributions: M.G. and D.C. planned the content of the paper and conducted the experimental work. O.T. and D.C. performed the characterisation of samples and coating. B.F. and H.C. were supervisors of the research work and participated in the writing and assessment of results.

Funding: This research received no external funding.

Acknowledgments: Dilara Celik expresses her deep thanks to European Commission for the provision of student researcher mobility at the University of RWTH Aachen under the Erasmus program.

Conflicts of Interest: The authors declare no conflict of interest.

\section{References}

1. Fang, T.Y.; Wang, W.H. Microstructural features of thermochemical processing in a Ti-6Al-4V alloy. Mater. Chem. Phys. 1998, 56, 35-47. [CrossRef]

2. Pan, L.; Wang, C.M.; Chen, Y.G.; Xiao, S.F. Recovery of Ti-6Al-4V Alloy Scrap by Hydrogenation and Hydride Sintering. Adv. Mater. Res. 2014, 1061-1062, 492-496. [CrossRef]

3. Ustinov, V.S.; Petrunko, A.N.; Olesov, Y.G.; Ognev, R.K. A Novelty in the Field of Titanium Powder Metallurgy; Springer: New York, NY, USA, 1982; pp. 2315-2321.

4. Goonan, T.G. Titanium Recycling in the United States in 2004. In Overview of Flow Studies for Recycling Metal Commodities in the United States; U.S. Geological Survey: Reston, VA, USA, 2004; pp. 1-16.

5. American Society for Metals. Titanium and Titanium Alloys; ASM International: Geauga County, OH, USA, 1982.

6. Prakash, P. Additive Manufacturing in Aerospace and Defence Sector: Strategy of India. J. Def. Stud. 2018, 12, 39-60.

7. Jardini, A.L.; Larosa, M.A.; Kaasi, A.; Kharmandayan, P. Additive Manufacturing in Medicine. Ref. Modul. Mater. Sci. Mater. Eng. 2017, 1-21. [CrossRef]

8. Brookes, K.J.A. 3D printing materials in Maastricht. Met. Powder Rep. 2015, 70, 68-78. [CrossRef]

9. Rotmann, B.; Lochbichler, C.; Friedrich, B. Challenges in titanium recycling-Do we need a new specification for secondary alloys? In Proceedings of the European Metallurgical Conference 2011 Resources Efficiency in the Non-Ferrous Metals Industry, Optimization and Improvement, Düsseldorf, Germany, 26-29 June 2011; pp. 1-15.

10. Oh, J.M.; Roh, K.M.; Lee, B.K.; Suh, C.Y.; Kim, W.; Kwon, H.; Lim, J.W. Preparation of low oxygen content alloy powder from Ti binary alloy scrap by hydrogenation-dehydrogenation and deoxidation process. J. Alloys Compd. 2014, 593, 61-66. [CrossRef]

11. Mitkov, M.; Božić, D. Hydride-dehydride conversion of solid Ti6Al4V to powder form. Mater. Charact. 1996, 37, 53-60. [CrossRef]

12. McCracken, C.G.; Robison, J.W.; Motchenbacher, C.A. Manufacture of HDH Low Oxygen Titanium-6aluminium4vanadium (Ti-6-4) Powder Incorporating a Novel Powder De-Oxidation Step; The European Powder Metallurgy Association: Shrewsbury, UK, 2009; pp. 7146-7152.

13. Gao, W.; Li, W.; Zhou, J.; Hodgson, P.D. Thermodynamics approach to the hydrogen diffusion and phase transformation in titanium particles. J. Alloys Compd. 2011, 509, 2523-2529. [CrossRef]

14. Tosetti, J.P.; Beneduce, F.; Rodrigues, D. Evaluation of Different Routes for HDH Processing of Ti-6Al-4V Alloy. Mater. Sci. Forum 2003, 416-418, 323-328. [CrossRef]

15. Azevedo, C.R.F.; Rodrigues, D.; Neto, F.B. Ti-Al-V powder metallurgy (PM) via the hydrogenation-dehydrogenation (HDH) process. J. Alloys Compd. 2003, 353, 217-227. [CrossRef]

16. Peng, Q.; Yang, B.; Liu, L.; Song, C.; Friedrich, B. Porous TiAl alloys fabricated by sintering of $\mathrm{TiH}_{2}$ and $\mathrm{Al}$ powder mixtures. J. Alloys Compd. 2016, 656, 530-538. [CrossRef]

17. Peng, Q.; Yang, B.; Friedrich, B. Porous Titanium Parts Fabricated by Sintering of $\mathrm{TiH}_{2}$ and Ti Powder Mixtures. J. Mater. Eng. Perform. 2018, 27, 228-242. [CrossRef]

18. Valdek, M.; Helmo, K.; Pritt, K.; Besterci, M. Characterization of Powder Particle. Methods 2001, 7, $22-34$. 
19. Geldart, D.; Abdullah, E.C.; Hassanpour, A.; Nwoke, L.C.; Wouters, I. Characterization of powder flowability using measurement of angle of repose. China Part 2006, 4, 104-107. [CrossRef]

20. Specification, S. Standard Specification for Titanium and Titanium Alloy Forgings 1; ASTM International: West Conshohocken, PA, USA, 2017.

21. Specification, S. Standard Specification for Titanium and Titanium Alloy Bars and Billets 1; ASTM International: West Conshohocken, PA, USA, 2017.

22. Specification, S. Standard Specification for Titanium and Titanium Alloy Strip, Sheet, and Plate 1; ASTM International: West Conshohocken, PA, USA, 2017.

23. Containing, M.; Than, L.; Percent, T.; Bars, T.A. Standard Specification for Powder Metallurgy (PM) Titanium and Titanium Alloy; ASTM International: West Conshohocken, PA, USA, 2017; pp. 12-15.

24. Singh, H.; Sidhu, T.S. Cold Spray Technology: Future of Coating Deposition Processes. Frat. Integr. Strutt. 2012, 22, 69-84.

25. Moridi, A.; Guagliano, M.; Dao, M. Cold spray coating: Review of material systems and future perspectives. Surf. Eng. 2014, 36, 369-395. [CrossRef]

26. Cetiner, D.; Paksoy, A.H.; Tazegul, O.; Baydogan, M.; Guleryuz, H.; Cimenoglu, H.; Atar, E. A novel fabrication method for a $\mathrm{TiO}_{2}$ layer over CoCr alloy. Surf. Eng. 2018. [CrossRef]

27. Vo, P.; Goldbaum, D.; Wong, W.; Irissou, E.; Legoux, J.; Chromik, R.R.; Yue, S. Cold-Spray Processing of Titanium and Titanium Alloys; Elsevier Inc.: Philadelphia, PA, USA, 2015.

28. Ajdelsztajn, L.; Jodoin, B.; Schoenung, J.M. Synthesis and mechanical properties of nanocrystalline Ni coatings produced by cold gas dynamic spraying. Surf. Coat. Technol. 2006, 201, 1166-1172. [CrossRef]

29. Xiong, Y.; Xiong, X.; Yoon, S.; Bae, G.; Lee, C. Dependence of Bonding Mechanisms of Cold Sprayed Coatings on Strain-Rate-Induced Non-Equilibrium Phase Transformation. J. Therm. Spray Technol. 2011, 20, 860-865. [CrossRef]

30. Wong, W.; Rezaeian, A.; Irissou, E.; Legoux, J.G.; Yue, S. Cold Spray Characteristics of Commercially Pure Ti and Ti-6Al-4V. Adv. Mater. Res. 2010, 89-91, 639-644. [CrossRef]

31. Wong, W.; Vo, P.; Irissou, E.; Ryabinin, A.N.; Legoux, J.G.; Yue, S. Effect of particle morphology and size distribution on cold-sprayed pure titanium coatings. J. Therm. Spray Technol. 2013, 22, 1140-1153. [CrossRef]

32. Bose, S.; Vahabzadeh, S.; Bandyopadhyay, A. Bone tissue engineering using 3D printing. Mater. Today 2013, 16, 496-504. [CrossRef]

33. Sun, P.; Fang, Z.Z.; Xia, Y.; Zhang, Y.; Zhou, C. A novel method for production of spherical Ti-6Al-4V powder for additive manufacturing. Powder Technol. 2016, 301, 331-335. [CrossRef]

34. Bhosle, V.; Baburaj, E.G.; Miranova, M.; Salama, K. Dehydrogenation of TiH2. Mater. Sci. Eng. A 2003, 356, 190-199. [CrossRef]

35. Bhattiprolu, V.S.; Johnson, K.W.; Ozdemir, O.C.; Crawford, G.A. Influence of feedstock powder and cold spray processing parameters on microstructure and mechanical properties of Ti-6Al-4V cold spray depositions. Surf. Coat. Technol. 2018, 335, 1-12. [CrossRef]

36. Wang, C.; Zhang, Y.; Wei, Y.; Mei, L.; Xiao, S.; Chen, Y. XPS study of the deoxidization behavior of hydrogen in $\mathrm{TiH}_{2}$ powders. Powder Technol. 2016, 302, 423-425. [CrossRef]

37. Goso, X.; Kale, A. Production of titanium metal powder by the HDH process. J. S. Afr. Inst. Min. Metall. 2011, 111, 203-210.

(C) 2018 by the authors. Licensee MDPI, Basel, Switzerland. This article is an open access article distributed under the terms and conditions of the Creative Commons Attribution (CC BY) license (http:/ / creativecommons.org/licenses/by/4.0/). 